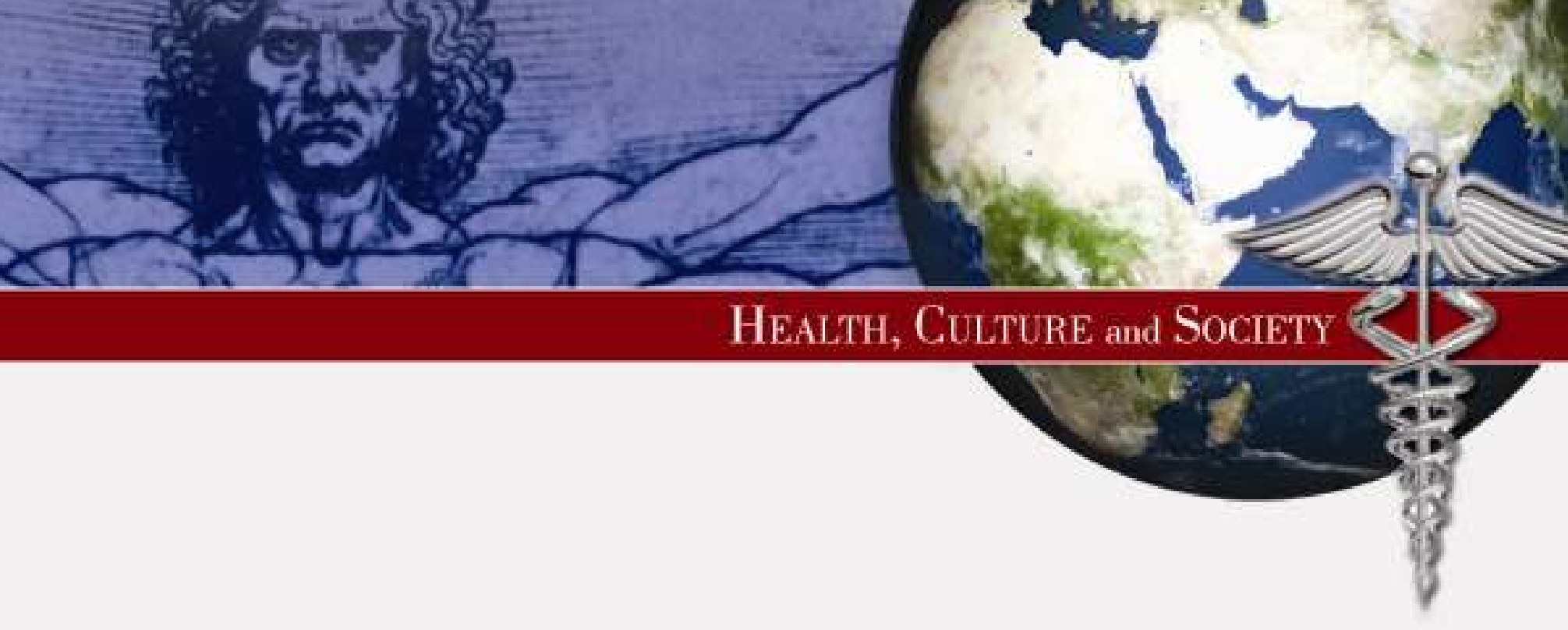

\title{
Global Health and the Demands of the Day
}

\section{Meg Stalcup \& StéphaneVerguet}

Volume 1, No. 1 (2011) | ISSN 2161-6590(online)

DOI 10.5195/hcs.2011.57| http://hcs.pitt.edu

\section{(c) $)$ BY-NC-ND}

This work is licensed under a Creative Commons Attribution-Noncommercial-No Derivative Works 3.0 United States License.

\section{ULIS D-Sull}

This journal is published by the University Library System of the University of Pittsburgh as part

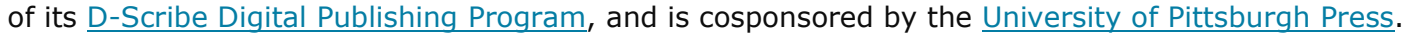




\section{Abstract}

We have two goals in this paper: first, to provide a diagnosis of global health and underline some of its blockages; second, to offer an alternative interpretation of what the demands for those in global health may be. The assumption that health is a good that requires no further explanation, and that per se it can serve as an actual modus operandi, lays the foundations of the problem. Related blockages ensue and are described using HIV prevention with a focus on vaginal microbicides as a case study. Taking health as a self-evident, and self-explanatory "good" limits other possible goods; and prevents inquiry into the actual practices of creating good. We propose that to create conditions under which global health could be reconstructed, problematization be taken up as a practice, around a series of questions asked in conjunction with those ever-urgent ones of how to ameliorate the condition of living beings.

Keywords: Global health; public health; HIV/AIDS; vaginal microbicides; anthropology; ethics 


\title{
Global Health and the Demands of the Day
}

\author{
Meg Stalcup ${ }^{1} \&$ StéphaneVerguet $^{2 \dagger}$
}

\section{Introduction}

"We shall," Max Weber said, "set to work and meet the 'demands of the day', in human relations as well as in our vocation."

Accepting Weber's mandate, in this article, we have two aims. One is to provide a preliminary diagnosis of the structure of the field of global health and some of its blockages as we see them. The other is to offer an alternative interpretation of what "the demands of the day" may be for researchers, workers and professionals in global health. What counts as "global health", meaning, what is included and excluded, is contested. Obviously not wholly new, global health is often placed in a lineage following tropical medicine and international health. ${ }^{4}$

Tropical medicine developed out of centuries of colonialism, but was founded as a discipline and institutionalized at the turn of the twentieth century. ${ }^{5}$ Originally characterized by a focus on vector-borne diseases,

${ }^{1}$ Meg Stalcup, Center for Biological Futures, Fred Hutchinson Cancer Research Center and Department of Anthropology, University of Washington.

${ }^{2}$ Stéphane Verguet, Department of Global Health, University of Washington. Correspondence should be addressed to verguet@uw.edu

${ }^{+}$Both authors contributed equally to this work

3 Max Weber, "Science as a Vocation," in The Vocation Lectures, ed. David Owen and Tracy B. Strong (Indianapolis: Hackett Publishing Company, 2004), 316.

${ }^{4}$ James E. Banta, "From International Health to Global Health," Journal of Community Health 26, no. 2 (2001); Tony Kirby, "Jeff Waage: Building a Coalition of Disciplines for Global Health," The Lancet 376, no. 9745 (2010); Theodore M. Brown, Marcos Cueto, and Elizabeth Fee, "The World Health Organization and the Transition From "International" To "Global" Public Health," American Journal of Public Health 96, no. 1 (2006); Sarah B. Macfarlane, Marian Jacobs, and Ephata E. Kaaya, "In the Name of Global Health: Trends in Academic Institutions," Journal of Public Health Policy 29(2008); David P. Fidler, "From International Sanitary Conventions to Global Health Security: The New International Health Regulations," Chinese Journal of International Law 4, no. 2 (2005).

${ }^{5}$ Gordon C. Cook, Tropical Medicine: An Illustrated History of the Pioneers (London and New York: Elsevier, 2007). 
its schools and institutes still abundantly dot the world landscape and contribute to efforts now labeled global health. $^{6}$

In the early years of the 1900s, "sanitation" and "hygiene", as well as the control of infectious diseases across borders, were becoming international efforts. ${ }^{7}$ These developed into the field of international health, which diversified and gained stature as a term around the middle of the twentieth century, especially with the creation of the World Health Organization (WHO). International health in the past encompassed much of what is presented as global health today: dramatic disease eradication campaigns - famously malaria, which failed and smallpox, which succeeded-and general public health writ large. Plans often linked socioeconomic development and health, and included international programs for education and training, family planning and immunizations. ${ }^{8}$

The World Health Organization's mid-1950s malaria program was actually one of the first initiatives to be labeled "global". Drawing from the conceptualization of the "global population problem" that gained strength in the 1970s, as well as the environmental movement's discourses around the threat of "global warming", by the mid1990s, with AIDS a full-blown pandemic, the idea of global health threats had proliferated. In tandem, the WHO, which was struggling politically and bureaucratically to define itself against the World Bank's encroachment via health financing, saw the utility in branding global health as a distinct field. ${ }^{9}$ The US Center for Disease Control began using the term "global infectious disease threats" in $1995 ;{ }^{10}$ soon after, the first Institute of Global Health was established at the University of California, San Francisco in 1999.

"Global health" includes, at least: people and populations in pursuit of health around the globe; and an assemblage of governmental and nongovernmental organizations, university departments, health, academic and policy professionals; and the political, social, economic and ethical relations within and between them. All these stakeholders are invested in distinct strategies towards specific objectives; their priorities and needs will come into conflict. Yet in global health, the moral terrain is already presumed to be known: health is a good, the content of which need only be determined by various technical verifications. The ethics of research trials are taken up as a question of working out details such as ascertaining the standard of care, and deciding if this can be provided. The use of health as a "good", which, implicitly, requires no further explanation, and, rather impracticably, can serve as an actual guide in action, presents us with a problem. At least, figuring out what kinds of goods health may be, and by what micropractices they are actualized, requires further work. Dedication to "saving lives by improving health" ${ }^{11}$ is properly aspirational: the task is then how to provide that aspiration with adequate equipment. ${ }^{12}$

6 Tropical health's growth as a discipline slowed and it was gradually shunted. Tellingly, a group of scholars in the mid-1990s argued that most diseases labeled "tropical" could be folded into the field of infectious disease, while there were noncommunicable health problems, found in all resource-poor settings, not just tropical ones, that were not receiving enough attention. See references [8-11] in Macfarlane, Jacobs, and Kaaya, "In the Name of Global Health: Trends in Academic Institutions."

7 David P. Fidler, "Emerging Trends in International Law Concerning Global Infectious Disease Control," Emerging Infectious Diseases 9, no. 3 (2003).

${ }^{8}$ Macfarlane, Jacobs, and Kaaya, "In the Name of Global Health: Trends in Academic Institutions."; Brown, Cueto, and Fee, "The World Health Organization and the Transition From "International" To "Global" Public Health."

${ }^{9}$ Brown, Cueto, and Fee, "The World Health Organization and the Transition From "International" To "Global" Public Health."

${ }^{10}$ Ibid.

${ }^{11}$ http://www.globalhealth.org/, "Global Health Council," (Accessed 20 July 2011).

12 Paul Rabinow and Gaymon Bennett, Synthetic Anthropos: Designs for Human Practice (Connexions, 2008). 
In global health the imperative to act seems all too obvious, and the vocational veneer unassailable. The demands of the day are generally formulated along these lines: too many people's lives are diminished due to illness, or they are dying; they have a right to health; the situation is urgent and hence we must act. This brooks no argument because health is taken to be self-explanatory and a good, thereby the amelioration of health constitutes ethical practice. In part because of the expansive justificatory power of health in this narrative, the field of global health attracts and comprises not only people from policy and medical sciences, but also from disciplines such as economics, agriculture, veterinary medicine, and environmental science. ${ }^{13}$ Health as a focus bestows the mantle of a shared vocation on these normally disparate spheres of professional activity, and value.

Two medical anthropologists ably covered this terrain in a 2009 review. ${ }^{14}$ They position anthropological work on global health as the disciplinary progeny of critical medical anthropology, which focuses on the socio-structural causes of disease. If babies of poor parents are dying from diarrhea, goes a paradigmatic example, this may be because of a political or economic system that fails to provide clean water for all. "The ultimate goal," wrote the authors, "is to reduce global health inequities and contribute to the development of sustainable and salutogenic, sociocultural, political, and economic systems". They admonish in conclusion:

the problems living beings face globally are too vast and the assaults on social justice and the environment too egregious for us to worry overly much about the sullying effects of doing applied work...being a principled "public intellectual" is sometimes not enough. We are called to apply our tools and knowledge, to seek interdisciplinary and intersectoral partnerships, and to both propose and engage directly in potential solutions. ${ }^{15}$

Their argument is congruent with those of global health advocates. The acclaimed "Treatment Action Campaign" (TAC) was founded in 1998 in South Africa to advocate for "A unified quality health care system which provides equal access to HIV prevention and treatment services for all people". ${ }^{16}$ The Treatment Action Campaign says that it will achieve its mission "to inform and support national advocacy efforts through its branches, providing a platform for people to mobilize and organize around HIV and related health rights". Struggling against the "assault on social justice" embodied in the obstacles faced by HIV positive people in getting access to antiretroviral therapies is clearly included among "the demands of the day". The call to apply tools and knowledge is likewise vocational: the question we ask is, how?

We argue that the fairly common dictate to "propose and engage directly in potential solutions" tends to skip a step, and an opportunity, for scholarly work. In fact, there need first be a refusal of first-order questions and demands in order to open a space for inquiry. ${ }^{17}$ There are multiple rationales at work in a problem-space which are

${ }^{13}$ Kirby, "Jeff Waage: Building a Coalition of Disciplines for Global Health."; Macfarlane, Jacobs, and Kaaya, "In the Name of Global Health: Trends in Academic Institutions."

${ }^{14}$ Craig R. Janes and Kitty K. Corbett, "Anthropology and Global Health," Annual Review of Anthropology 38(2009): 169.

${ }^{15}$ Ibid.: 178.

${ }^{16}$ http://www.tac.org.za/community/about, "Treatment Action Campaign."

17 First-order observations tell us what is happening. Second-order observations shift frames so as to tell us how the first order observations are made. Second-order observations mark criteria and distinctions, assumptions and the limits of categories. Neither type of observation is privileged: they have different objects and provide different kinds of information. Niklas 
not self-evident, nor necessarily equally adequate to the formulation of the situation and ways to deal with it. Quite pragmatically, assuming that the problem is, say, health disparities, and absorbing that problem into the even more general categories of poverty and structural violence, may not provide sufficient analytical purchase. Potts et al. note, ${ }^{18}$ for example:

The presumption...that poverty increases vulnerability to HIV infection is challenged by studies such as an analysis of recent Demographic and Health Surveys (DHSs) from Africa, which shows a strong positive correlation between HIV prevalence and wealth in eight countries examined...Among Kenyan women, HIV prevalence is $3.9 \%$ in the lowest economic quintile and $12 \%$ in the highest.

Doing "applied work" too often indicates taking on the problems of one's subjects - which in the case of this paper are those who work in global health - as one's own. We suggest that doing so is not, in fact, an act of partnership towards a goal of mutual flourishing, of which "health" is surely one part. One role of inquiry is to produce the intellectual tools to reconstruct a situation. ${ }^{19}$ A pressing task for scholars consists in posing questions about the problems as posed. In this spirit, what we propose here is a brief critique of some of the ways in which "goods" in global health function both to animate and to block practice. This is critique in the sense of trying to bring to light the limitations of thinking, acting and relating. Which is to say, health as a good is only problematic to the extent that we overestimate its ability to indicate right practices.

Advocacy, in meaning and in practice, is fighting for a cause. The rightness of that cause has already been decided. While the approach is almost certainly coherent within a given line of reasoning and valuation, the metric is not necessarily the same as, to give only one illustration, that applied from the perspective of the public health needs of a population. Those who work on garnering funding, either for scientific research into a given approach to disease or to raise awareness and form public opinion, have often championed a specific approach in which they are invested. One example is the development of HIV prevention strategies that women can control and use independently of a sexual partner who is unwilling to use protective measures. Pointedly, who can argue against this? Women should have options and the opportunity to choose between them. Yet, while the best vaginal microbicide gels up to now have shown $54 \%$ effectiveness in the highest adherers,${ }^{20}$ male circumcision has a $60 \%$ effect on the reduction of HIV transmission ${ }^{21}$ and, as one article dryly observed, adherence is not much of a

Luhmann, Observations on Modernity, ed. Timothy Lenoir and Hans Ulrich Gumbrecht (Stanford: Stanford University Press, 1998).

${ }^{18}$ Malcolm Potts et al., "Reassessing HIV Prevention," Science 320(2008): 749.

19 John Dewey, Reconstruction in Philosophy (New York: Henry Holt and Company, 1920).

${ }^{20}$ Quarraisha Abdool Karim et al., "Effectiveness and Safety of Tenofovir Gel, an Antiretroviral Microbicide, for the Prevention of HIV Infection in Women," Science (2010).

${ }^{21}$ Bertran Auvert et al., "Randomized, Controlled Intervention Trial of Male Circumcision for Reduction of HIV Infection Risk: The Anrs 1265 Trial. ," PloS Medicine 2, no. 11 (2005); Abdool Karim et al., "Effectiveness and Safety of Tenofovir Gel, an Antiretroviral Microbicide, for the Prevention of HIV Infection in Women." 
problem. $^{22}$ Debate over how support should be allocated between vaginal microbicides, male circumcision, and other HIV prevention interventions is reasonable and necessary: we point to that debate as a place wherein there is a role for thought about the conceptualization of the problem, and how solutions are implemented. Decisions have to be made about research and funding agendas; here is a situation in which to apply the test of reality: what is the good sought? What are the practices by which it will be created?

This brings us to a paired blockage. If the scholar believes that his or her position is to throw one's lot in with the solutions advocated, there is one, an acceptance that the correct problem has been identified, as well as, two, adoption of that specific solution. It is our opinion that neither can be accepted per se. If what should be done is always already assumed to be known, and the request made to researchers is simply how to do something, there is no possibility of asking different questions, and reaching different answers. There are reasons, then, to refuse the firstorder demand for answers, not only despite their urgency but because of it. The list of urgent needs provided as the rationale for the call for action, many of which have remained unchanged throughout the history of public health, serves equally to indicate that the way some problems have been formulated and approached has not meet even internally defined goals.

\section{Case Study: HIV Prevention.}

A significant part of global health efforts are oriented around the simple formulation: disease and health disparities should be addressed by advances in biomedical technologies. This is also an oft-knocked straw man, as it seems to postulate an adequate health care system into which a new technology could be integrated, an ideal so far from reality that even the technophilic dismiss it. Chris Elias, the president of PATH (as the Program for Appropriate Technology in Health is called) said,

\footnotetext{
The most unproductive debate in global health is whether we should work on technologies or systems...you have to do it all, in an integrated way. The technology has to be designed for the system, for people who are undertrained, for inadequacies. You have to design the technologies for the system that is going to use it, as well as get behavior change in the providers and those treated. ${ }^{23}$
}

Despite dismissal of the technology/heath systems opposition, constructing or reconstructing health care systems-some still struggling from cuts enacted under the Washington Consensus ${ }^{24}$-would require a massive input of resources, most of which are set to go towards inarguably important technological fixes, from prophylactic antiretroviral HIV pills to new antigens for vaccine-preventable diseases. The agreed upon good of "health" has not yet been rendered into consensus about how to achieve it. Instead, there is a history of well-rehearsed debates about how health can be put into practice and produced through projects.

\footnotetext{
22 Nancy S. Padian et al., "Weighing the Gold in the Gold Standard: Challenges in HIV Prevention Research," AIDS 24, no. 5 (2010): 627.

${ }^{23}$ Chris Elias, "Can Seattle Save the World?" (Town Hall, Seattle, WA, 26 April 2011).

24 James Pfeiffer and Mark Nichter, "What Can Critical Medical Anthropology Contribute to Global Health? A Health Systems Perspective," Medical Anthropology Quarterly 22, no. 4 (2008).
} 
Many resources are used on "vertical" interventions such as the HIV treatment programs that the U.S. President's Emergency Plan for AIDS Relief (PEPFAR) ${ }^{25}$ tends to fund, or polio eradication campaigns ${ }^{26}$ and, in a zero-sum game, this means less money and effort can potentially be spent on other health sectors, such as primary care. ${ }^{27}$ A growing emphasis on "integrated care", a dusted-off version of an earlier World Health Organization precept ${ }^{28}$ can be seen as an attempt to refuse the zero-sum formulation. The Mexican "diagonal approach" ${ }^{29}$ for example, combines vertical interventions selected to address priority primary health care needs, ${ }^{30}$ through which the "horizontal" health care system is at least partially strengthened. But resources also have to be coordinated in such a way as to coherently address the problems besetting a national population. ${ }^{31}$ Even the best solution in a narrow sense can backfire in the context of the whole. Aid money funneled through NGOs can strengthen those NGOs, for instance, rather than strengthening a basic health care system, and can also pull valuable human skill towards those efforts, and hence away from others. ${ }^{32}$

Not all the stumbling blocks that have appeared along the path of the technical amelioration of global health can be ascribed to divergent philosophies about the allocation of resources however. The history of the development of anti-HIV vaginal microbicide gels, including the design of randomized controlled trials, serves here as a study of other types of problems.

Microbicides are chemical agents that can be used intravaginally with the goal of protecting users against sexually transmitted infections, including HIV. ${ }^{33}$ As women now account for $60 \%$ of the 22.5 million infected subjects in sub-Saharan Africa, ${ }^{34}$ a vaginal microbicide that could empower women against HIV infection has much potential for use. The first-generation of microbicidal gels were detergents, which contain polyanion compounds that, unfortunately, "have limited potency in vitro, particularly against the most commonly transmitted strains of HIV-1"; 35 two of the gels compromised the integrity of the genital tract, increased inflammation and interfered with immune function. ${ }^{36}$ The efficacy trials of these products produced, in the muted language of the genre, disappointing

${ }^{25}$ http://www.pepfar.gov, "The U.S. President's Emergency Plan for AIDS Relief "(Accessed 20 July 2011).

${ }^{26}$ http://www.polioeradication.org, "Global Polio Eradication Initiative," (Accessed 20 July 2011).

${ }^{27}$ Anne Mills, "Mass Campaigns Versus General Health Services: What Have We Learnt in 40 Years About Vertical Versus Horizontal Approaches?," Bulletin of the World Health Organization 83, no. 4 (2005).

${ }^{28}$ C.L. Gonzalez, "Mass Campaigns and General Health Services," (Geneva: World Health Organization, 1965).

${ }^{29}$ Jaime Sepulveda et al., "Improvement of Child Survival in Mexico: The Diagonal Approach," Lancet 368(2006).

30 Julia A. Walsh and Kenneth S. Warren, "Selective Primary Health Care," New England Journal of Medicine 301, no. 18 (1979); Marcos Cueto, "The Origins of Primary Health Care and Selective Primary Health Care," American Journal of Public Health 94 , no. 11 (2004).

31 http://www.wbur.org/npr/137762573/paul-farmer-examines-haiti-after-the-earthquake, "Paul Farmer Examines Haiti 'after the Earthquake'," in Fresh Air (USA: WBUR Boston, 2011).

32 Pfeiffer and Nichter, "What Can Critical Medical Anthropology Contribute to Global Health? A Health Systems Perspective," 411.

${ }^{33}$ Alan Stone, "Microbicides: A New Approach to Preventing HIV and Other Sexually Transmitted Infections," Nature Reviews Drug Discovery 1(2002).

34 UNAIDS, "AIDS Epidemic Update," (Geneva2009).

35 Robert M. Grant et al., "Whither or Wither Microbicides?," Science 321, no. 5888 (2008); Gita Ramjee, "Microbicide Research: Current and Future Directions," Current Opinion in HIV and AIDS 5(2010): 317.

${ }^{36}$ Ramjee, "Microbicide Research: Current and Future Directions." 
results. ${ }^{37}$ The first six candidates showed no effect on decreasing HIV transmission, and those two that produced "epithelial barrier disruption" actually showed a trend towards increasing risk of infection. ${ }^{38}$

Another reason for the early candidates' "disappointing results" could be that semen decreases the effectiveness of these microbicides by enhancing the virus with amyloid-like aggregates called 'semen-derived enhancer of viral infection' (SEVI). ${ }^{39}$ To repeat one of the droller lines in the microbicide literature, "The identification of microbicides that are active in the presence of semen/SEVI would be a positive step towards the development of effective products. ${ }^{, 40}$

What happened such that these products were chosen, and so many trials carried out competitively? This could be chalked up as unavoidable dead-ends along the road to progress, but we think rather that there was a lack of attention to the good at stake, and to the question of if the being actions taken would produce the desired good. Grant et al. point out, "observations of polyanion-mediated enhancement of such viruses, both in vitro and in vivo, were made 15 to 20 years ago". ${ }^{41}$ That subsequent testing of the polyanions was conducted on thousands of women, they go on, "raises concerns about the preclinical research that was performed on these microbicide candidates". ${ }^{4}$ Grant suggests that, on one side, there was pressure to fast-track something, and "multiple funding agencies or institutions each felt the need to adopt its own polyanion candidate". 43 The products were thought to be generally safe - despite early tests of nonoxynol-9 which showed inflammation - but inhibiting sexual transmission of HIV turned out to be much harder than originally thought.

We shift to a different type of explanation for the dismal track record of these trials, as well as those of other interventions, namely, "poor adherence": participants did not always use the product, or, when they did, it wasn't always used quite right. This can be due in part to lack of attention to the biophysical properties - consistency and formulation, for example - of microbicide gel vehicles on the part of researchers, an evocative indicator of the need for "interdisciplinary and intersectoral partnerships". ${ }^{4}$

To understand this particular issue, one can think of sunscreen. To prevent sunburn, sunscreen must be adequately distributed onto the skin's vulnerable locations. This requires the appropriate deployment of the sunscreen, which depends on both biophysical aspects of the potion - its wateriness for instance - and the coating mechanism - the manner in which the hand coats the skin. The same rationale applies for the delivery of a microbicide gel onto the vaginal epithelium. In order to work effectively, the microbicide's active ingredients must

${ }^{37}$ Ibid; Ian McGowan, "Microbicides for HIV Prevention: Reality or Hope?," Curr Opin Infect Dis 23(2010); Grant et al., "Whither or Wither Microbicides?."

38 Ramjee, "Microbicide Research: Current and Future Directions," 317. L Van Damme et al., "Effectiveness of Col-1492, a Nonoxynol-9 Vaginal Gel, on HIV-1 Transmission in Female Sex Workers: A Randomised, Controlled Trial," Lancet 360(2002).

39 NR Roan et al., "The Cationic Properties of Sevi Underlie Its Ability to Enhance Human Immunodeficiency Virus Infection," $J$ Virol 83(2009); J Münch, E Rücker, and L Ständker, "Semen-Derived Amyloid Fibrils Drastically Enhance HIV Infection," Cell 131(2007); K Kyeong-Ae et al., "Sevi and Semen Impair the Anti-HIV-1 Activity of Drugs and Microbicides," Antiviral Res 82(2009).

${ }^{40}$ Ramjee, "Microbicide Research: Current and Future Directions," 317.

${ }^{41}$ Grant et al., "Whither or Wither Microbicides?."

42 Ibid.

43 Ibid.

${ }^{44}$ Janes and Corbett, "Anthropology and Global Health," 178. 
be appropriately distributed in order to target tissue sites where HIV transmission occurs. ${ }^{45}$ Importantly, this has implications in terms of the gel's design and the application instructions that should be given to participants of clinical trials.

There is a wait time between the application of a microbicide gel and maximally safe sex. A gel that is highly viscous - say as viscous as honey - may require several hours to spread effectively; a less viscous, watery gel may require only a few minutes. ${ }^{46}$ The gel's viscosity dictates texture and governs flow; it is one of several physical attributes that link a user's preference and physical functionality. A thick gel might be preferred to a thin gel, which is potentially messy. But, the desirability of a longer wait time will depend on the user's situation and personal preferences. ${ }^{47}$ The biophysical and behavioral attributes of microbicide gels are intrinsically linked: the gel first must be physically realistic (a very thick gel is never going to spread very fast), then acceptable to the user, and finally applied in a way promoting timely, effective coating.

This might seem to belabor the point, since clearly, putting gel formulation considerations and user preference together in designing trials would facilitate greater user adherence, enhance effectiveness and produce better results. Yet, clinical trials quite often did not take into account such considerations, in particular in the application instructions given to participants. The CAPRISA 004 trial reduced the incidence of HIV infection, a success on the path to a microbide gel product. ${ }^{48}$ In the trial, women were instructed to insert one dose of gel within 12 hours before sex and a second dose of gel as soon as possible within 12 hours after sex, modeled on the timing of another medication that prevented mother-to-child HIV transmission. ${ }^{49}$ The gel vehicle used in the CAPRISA 004 trial, however, can take less than an hour to completely coat the vaginal epithelium. ${ }^{50}$

There are multiple explanations for this history overall, in which health was the directing goal, but was too underdetermined to provide direction to the diverse group of actors. One explanation is the compartmentalization of research: there is a lack of communication between different research disciplines within universities and the small companies engaged in microbicide development. A second is that a lot must be taken into account, tested and communicated at each step in the design of a product: the biophysical features of a polymeric gel intrinsically affect its effectiveness and have behavioral implications, which ultimately impact user adherence. Third, none of the major pharmaceutical companies are involved in microbicide development, as it is not seen as potentially profitable, and thus their expertise, which of course would come at a high cost, has not been brought to bear. ${ }^{51}$

${ }^{45}$ DH Owen et al., "Biophysical Analysis of Prototype Microbicide Gels," Journal of Pharmaceutical Sciences 96, no. 3 (2007).

${ }^{46}$ AJ Szeri et al., "A Model of Transluminal Flow of Anti-HIV Microbicide Vehicle: Combined Elastic Squeezing and Gravitational Sliding," Physics of Fluids 20(2008).

47 Stéphane Verguet, Holt B Young, and AJ Szeri, "Increasing the Effectiveness of Vaginal Microbicides: A Biophysical Framework to Rethink Behavioral Acceptability," PLOS ONE 5, no. 11 (2010).

${ }^{48}$ Abdool Karim et al., "Effectiveness and Safety of Tenofovir Gel, an Antiretroviral Microbicide, for the Prevention of HIV Infection in Women."

49 Ibid.

${ }^{50}$ AJ Szeri et al., "Predicting Intravaginal Microbicide Distributio from Properties of Both Gel and Vagina: Advanced Biomechanical Modeling," in Microbicides (New Delhi, India2008); Stéphane Verguet, "Transport Phenomena in Microfluidics and Microbicide Drug Delivery Systems" (PhD Thesis, University of California, Berkeley, 2008); Szeri et al., "A Model of Transluminal Flow of Anti-HIV Microbicide Vehicle: Combined Elastic Squeezing and Gravitational Sliding."

${ }^{51}$ Grant et al., "Whither or Wither Microbicides?." 
Holmberg, in his history of blockages in how the US has dealt with HIV and AIDS, points to the problems of mathematical modeling, in which "Reminiscent of the Wizard of Oz's warning 'Ignore the man behind the curtain,' many of the assumptions... are large, based on scant data and not always clear or even presented to the reader":

[...] the mathematics can be obtuse and the result predetermined by the assumptions put into the model. Readers of articles in general scientific, medical or public health literature will not be able to understand the calculus, other than in a general way, involved in most mathematical models. ${ }^{52}$

We add that a converse corollary is also true: those creating models may not know accurately the limitations of the data collected, or have sufficient knowledge about their interaction on the ground to be able to produce meaningful quantitative data. There is a need for researchers to develop their capacities, to be given the opportunity to observe, participate and iteratively contribute to the development and design of research at multiple levels of a research project, such that narrow specialization in one area would be balanced with at least some understanding of the research in different parts of the project. ${ }^{53}$

This relates to research design flaws identified by Padian and colleagues, who in a review of randomized controlled trials (RCTs) for HIV prevention found, stunningly, that "almost $90 \%$ of RCTs of interventions for prevention of sexual transmission of HIV have delivered flat results" ${ }^{54}$ Some of this failure can be chalked up to defective products, such as the early microbicides. However, Padian et al. reported that the majority of the flat results were attributable, at least in part, to issues related to trial design and/or implementation. ${ }^{55}$ The difficult work of turning ideas into research in the field, especially given the multi-faceted nature of public health, has been done without sufficient attention to the operations research aspects of trial implementation, while relatively greater attention has been paid to the production of scientific and academic results.

One of the ways that global health is made to cohere is by the presumption of a shared good-health-and this acts as a moral imperative. One question is, what kind of moral imperative is this? Second, how is it turned into practices of funding, research, clinical trials, modeling and evaluation? Having discussed the research and development of vaginal microbicide gels, we suggest that the regular and explicit gauging what is being counted as good, and in what ways, would be a useful tool in global health.

\section{Diagnosis}

In this piece we're dealing with one problem of limited character, but significant effect. The problem of the good, part of which is the inability to pose it as a problem, has a capillary relationship to the blockages we describe.

\footnotetext{
52 Scott D. Holmberg, Scientific Errors and Controversies in the U.S. HIV/AIDS Epidemic: How They Slowed Advances and Were Resolved (Westport, CT and London: Praeger, 2008), 9.

53 http://www.cugh.org/about/background - ten-recommendations, "Key Needs for the 21st Century: Ten Recommendations from the Workforce Sustainability Conference of September 23-25, 2007" (San Francisco, 2007).

${ }^{54}$ Padian et al., "Weighing the Gold in the Gold Standard: Challenges in HIV Prevention Research."

${ }^{55}$ Ibid.
} 
Although we are oriented toward reconstruction in practices and institutions in global health, this is neither a summary judgment of global health, nor do we suggest that these problems are wholly condemning of this complex and heterogeneous assemblage. Rather, there are zones in which problems are going on. These zones have effects and should be identified.

Returning to the call for action by the two anthropologists quoted in the beginning of this piece, they passionately ask that scholarship be put to the service of those problems faced by living beings. With this, we are in full agreement. The question we pose is, what can that mean? What are the blockages presented by taking health as a self-evident, and self-explanatory good? We have identified some in the case study of HIV prevention. The underdetermination of "health" can obscure what may be competing agendas among those providing services, or the needs of different populations. Health can be used to justify projects that deserve greater scrutiny, or at least coordination, as in the case of competing microbicide trials testing similar products. These are blockages identifiable within global health as a system or assemblage; there are others from the position of the subject. Of these, we mention the pursuit of a profession, and a vocation.

People who have dedicated their lives to providing health care have grappled with the problems that arise in domestic or international public health, advocacy or medical research in real and significant ways; much work has surely been vocational. It is also the case that pragmatic rewards in global health may be quite great, including good salary, flexible work conditions, paid travel, and intellectual gratification. Some people work in global health for these reasons, or also for these reasons. In parallel, global health is touted as a felicitous combination that generates both money and health: doing good is good business. ${ }^{56}$ What is problematic in this is the foreclosure of inquiry into what kinds of the goods these may be, and what the ethical practices for pursuing them are, as well as other possible forms of good. The two we will discuss briefly are practices of self-care and the fulfillment of curiosity.

Individuals want to "do global health" for a mix of reasons. The fact that there is almost certainly need at home is well-known. But global health is more exotic than local health: the unknown is exciting, challenging oneself is rewarding. The element of self-formation and self-care is not incidental nor is it usefully collapsed into care for others; we cannot care for others if we don't care for ourselves. ${ }^{57}$ What is more, those who go on in global health to "propose and engage directly in potential solutions" will be confronted with the need to make decisions for which the simple equation of health and good will be evidently inadequate.

Regarding scientific curiosity, Holmberg, who spent nearly 20 years in the CDC's Division of HIV/AIDS Prevention, wrote,

Most scientists do science because, as for mountain climbers, the mountain beckons. Unlike mountain climbers, however, they can ascribe their motivations to a greater social good, and so hide the fact that they do science because it is really interesting. ${ }^{58}$

\footnotetext{
${ }^{56}$ http://www.wghalliance.org/about/mission, "Washington Global Health Alliance," (Accessed 20 July 2011).

57 Michel Foucault, The Hermeneutics of the Subject: Lectures at the Collège De France 1981-1982, ed. Frédéric Gros, trans. Graham Burchell (New York: Palgrave Macmillan, 2005).

${ }^{58}$ Holmberg, Scientific Errors and Controversies in the U.S. HIV/AIDS Epidemic: How They Slowed Advances and Were Resolved, 2.
} 
The pursuit of curiosity, which may sustain the scientist when the potential benefits to health are too distant or intangible, is also its own virtue.

Stating that health is a good, implicitly assuming it requires no further explanation, and that per se it can serve as an actual modus operandi, lays the foundations of a problem: it shuts down inquiry into what practices might actually ameliorate the current situation, and what capacities we need to develop or intensify in order to do so. In view of the blockages we have described, we ask the question of what could be done in order for reconstructive practices to become possible in global health. ${ }^{59}$ If we refuse a choice between global health research as technical work in the name of the urgency of health, wealth and security, or a subordinate commitment to what are presumed to be self-evident problems of social justice or health disparities, what is left? ${ }^{60}$

We move instead towards practices that "test of reality, of contemporary reality, both to grasp the points where change is possible and desirable, and to determine the precise form this change should take. ${ }^{\prime 61} \mathrm{We}$ propose, as a step towards creating the conditions under which global health could be reconstructed, ${ }^{62}$ to take up problematization as a practice, ${ }^{63}$ around a series of questions to be asked in conjunction with those ever-urgent ones of how to ameliorate the condition of living beings. If producing health is our goal, then our questions must include: Is that what our practices are doing? What do our actions leave out? What needs to be in place in order to make it happen? ${ }^{64}$ And, what is the work that we must do on ourselves in order to be able to ask the right questions and take right action?

\section{Bibliography}

Auvert, Bertran, Taljaard D., Lagarde E., Sobngwi-Tambekou J., Sitta R., and Puren A. "Randomized, Controlled Intervention Trial of Male Circumcision for Reduction of HIV Infection Risk: The Anrs 1265 Trial. ." PloS Medicine 2, no. 11 (2005): 1112-22.

Banta, James E. "From International Health to Global Health." Journal of Community Health 26, no. 2 (2001): 7376-76.

\footnotetext{
59 http://reconstructing-sciences.net/collections/knowledge-and-truth, "Reconstructing the Sciences," ed. ARC / Center for Biological Futures (Accessed 20 July 2011).

60 Thanks to Gaymon Bennett for this turn of phrase

${ }^{61}$ Michel Foucault, "What Is Englightenment?," in Ethics: Subjectivity and Truth, ed. Paul Rabinow (New York: The New Press, 1997).

62 Dewey, Reconstruction in Philosophy.

${ }^{63}$ Michel Foucault, "Polemics, Politics and Problematizations," in Aesthetics, Method and Epistemology, ed. James D Faubion (New York: New Press, 1998).

64 Thanks to Gaymon Bennett and Paul Rabinow for suggestions towards this formulation of these questions
} 
Brown, Theodore M., Marcos Cueto, and Elizabeth Fee. "The World Health Organization and the Transition From "International" To "Global" Public Health." American Journal of Public Health 96, no. 1 (2006): 62-72.

Cook, Gordon C. Tropical Medicine: An Illustrated History of the Pioneers. London and New York: Elsevier, 2007.

Cueto, Marcos. "The Origins of Primary Health Care and Selective Primary Health Care." American Journal of Public Health 94, no. 11 (2004): 1864-74.

Dewey, John. Reconstruction in Philosophy. New York: Henry Holt and Company, 1920.

Elias, Chris. "Can Seattle Save the World?", Town Hall, Seattle, WA, 26 April 2011.

Fidler, David P. "Emerging Trends in International Law Concerning Global Infectious Disease Control." Emerging Infectious Diseases 9, no. 3 (2003): 285-90.

—. "From International Sanitary Conventions to Global Health Security: The New International Health Regulations." Chinese Journal of International Law 4, no. 2 (2005): 325-92.

Foucault, Michel. The Hermeneutics of the Subject: Lectures at the Collège De France 1981-1982. Translated by Graham Burchell. Edited by Frédéric Gros. New York: Palgrave Macmillan, 2005.

- "Polemics, Politics and Problematizations." In Aesthetics, Method and Epistemology, edited by James D Faubion. New York: New Press, 1998.

—. "What Is Enlightenment?" In Ethics: Subjectivity and Truth, edited by Paul Rabinow. New York: The New Press, 1997.

Gonzalez, C.L. "Mass Campaigns and General Health Services." Geneva: World Health Organization, 1965.

Grant, Robert M., Dean Hamer, Thomas Hope, Rowena Johnston, Joep Lange, Michael M. Lederman, Judy Lieberman, Christopher J Miller, John P. Moore, Donald E. Mosier, Douglas D. Richman, Robert T. Schooley, Marty S. Springer1, Ronald S. Veazey, and Mark A. Wainberg. "Whither or Wither Microbicides?" Science 321, no. 5888 (2008): pp. 532-34

Holmberg, Scott D. Scientific Errors and Controversies in the U.S. HIV/AIDS Epidemic: How They Slowed Advances and Were Resolved. Westport, CT and London: Praeger, 2008. 
http://reconstructing-sciences.net/collections/knowledge-and-truth "Reconstructing the Sciences." edited by ARC / Center for Biological Futures, Accessed 20 July 2011.

http://www.cugh.org/about/background\#ten-recommendations "Key Needs for the 21st Century: Ten Recommendations from the Workforce Sustainability Conference of September 23-25, 2007." San Francisco, 2007.

http://www.globalhealth.org/ "Global Health Council." (Accessed 20 July 2011).

http://www.pepfar.gov "The U.S. President's Emergency Plan for AIDS Relief " (Accessed 20 July 2011).

http://www.polioeradication.org "Global Polio Eradication Initiative." (Accessed 20 July 2011).

http://www.tac.org.za/community/about "Treatment Action Campaign."

http://www.wbur.org/npr/137762573/paul-farmer-examines-haiti-after-the-earthquake "Paul Farmer Examines Haiti 'after the Earthquake'." In Fresh Air. USA: WBUR Boston, 2011.

http://www.wghalliance.org/about/mission "Washington Global Health Alliance." Accessed 20 July 2011.

Janes, Craig R., and Kitty K. Corbett. "Anthropology and Global Health." Annual Review of Anthropology 38 (2009): 167-83.

Karim, Quarraisha Abdool, Salim S. Abdool Karim, Janet A. Frohlich, Anneke C. Grobler, and et al. "Effectiveness and Safety of Tenofovir Gel, an Antiretroviral Microbicide, for the Prevention of HIV Infection in Women." Science (2010).

Kirby, Tony. "Jeff Waage: Building a Coalition of Disciplines for Global Health." The Lancet 376, no. 9745 (2010): 949.

Kyeong-Ae, K, S Jiang, F Kirchhoff, and J Muench. "Sevi and Semen Impair the Anti-HIV-1 Activity of Drugs and Microbicides." Antiviral Res 82 (2009): A64-A164. 
Macfarlane, Sarah B., Marian Jacobs, and Ephata E. Kaaya. "In the Name of Global Health: Trends in Academic Institutions." Journal of Public Health Policy 29 (2008): 383-401.

McGowan, Ian. "Microbicides for HIV Prevention: Reality or Hope?" Curr Opin Infect Dis 23 (2010): 26 - 31.

Mills, Anne. "Mass Campaigns Versus General Health Services: What Have We Learnt in 40 Years About Vertical Versus Horizontal Approaches?" Bulletin of the World Health Organization 83, no. 4 (2005): 315-16.

Münch, J, E Rücker, and L Ständker. "Semen-Derived Amyloid Fibrils Drastically Enhance HIV Infection." Cell 131 (2007): 1059-71.

Owen, DH, JJ Peters, SL Kieweg, and et al. "Biophysical Analysis of Prototype Microbicide Gels." Journal of Pharmaceutical Sciences 96, no. 3 (2007): 661-69.

Padian, Nancy S., Sandra I. McCoy, Jennifer E. Balkus, and Judith N. Wasserheitd. "Weighing the Gold in the Gold Standard: Challenges in HIV Prevention Research." AIDS 24, no. 5 (2010): 621-35.

Pfeiffer, James, and Mark Nichter. "What Can Critical Medical Anthropology Contribute to Global Health? A Health Systems Perspective." Medical Anthropology Quarterly 22, no. 4 (2008): 410-15.

Potts, Malcolm, Daniel T. Halperin, Douglas Kirby, Ann Swidler, and Elliot Marseille. "Reassessing HIV Prevention." Science 320 (2008).

Rabinow, Paul, and Gaymon Bennett. Synthetic Anthropos: Designs for Human Practice: Connexions, 2008.

Ramjee, Gita. "Microbicide Research: Current and Future Directions." Current Opinion in HIV and AIDS 5 (2010): $316-21$.

Roan, NR, J Munch, N Arhel, and et al. "The Cationic Properties of Sevi Underlie Its Ability to Enhance Human Immunodeficiency Virus Infection." J Virol 83 (2009): 73 - 80.

Sepulveda, Jaime, Flavia Bustreo, Roberto Tapia, Juan Rivera, Rafael Lozano, and et al. "Improvement of Child Survival in Mexico: The Diagonal Approach." Lancet 368 (2006): 2017-27.

Stone, Alan. "Microbicides: A New Approach to Preventing HIV and Other Sexually Transmitted Infections." Nature Reviews Drug Discovery 1 (2002): 77-985. 
Szeri, AJ, SC Park, S Verguet, and DF Katz. "Predicting Intravaginal Microbicide Distributio from Properties of Both Gel and Vagina: Advanced Biomechanical Modeling." In Microbicides. New Delhi, India, 2008.

Szeri, AJ, SC Park, S Verguet, A Weiss, and DF Katz. "A Model of Transluminal Flow of Anti-HIV Microbicide Vehicle: Combined Elastic Squeezing and Gravitational Sliding." Physics of Fluids 20 (2008): 083101 (10 pages).

UNAIDS. "AIDS Epidemic Update." Geneva, 2009.

Van Damme, L, G Ramjee, M Alary, B Vuylsteke, V Chandeying, H Rees, and et al. "Effectiveness of Col-1492, a Nonoxynol-9 Vaginal Gel, on HIV-1 Transmission in Female Sex Workers: A Randomised, Controlled Trial." Lancet 360 (2002): 971-77.

Verguet, Stéphane. "Transport Phenomena in Microfluidics and Microbicide Drug Delivery Systems." PhD Thesis, University of California, Berkeley, 2008.

Verguet, Stéphane, Holt B Young, and AJ Szeri. "Increasing the Effectiveness of Vaginal Microbicides: A Biophysical Framework to Rethink Behavioral Acceptability." PLoS ONE 5, no. 11 (2010).

Walsh, Julia A., and Kenneth S. Warren. "Selective Primary Health Care." New England Journal of Medicine 301, no. 18 (1979): 967-74.

Weber, Max. "Science as a Vocation." In The Vocation Lectures, edited by David Owen and Tracy B. Strong. Indianapolis: Hackett Publishing Company, 2004 